\title{
Determinants of First Line Antiretroviral Treatment Failure among Patients on Highly Active Antiretroviral Therapy in selected Public Hospitals Jimma, Southwest Ethiopia a Case Control Study
}

\section{Amrachu Bekele Asfaw ( $\square$ amribekele@gmail.com )}

Maji Primary Hospital, Maji District, Bench Maji Zone, Southern People, Nations and Nationalities, Ethiopia https://orcid.org/0000-0002-4575-3191

\section{Aderajew Nigusie Tekelehaimanot}

Department of population and family health, Jimma university

\section{Tamirat Shewanew}

Jimma University College of Public Health and Medical Sciences

\section{Esayas Kebede Gudina}

Jimma medical center

\section{Masrie Getnet}

Jimma University College of Public Health and Medical Sciences

\section{Demuma Amdisa}

Jimma University College of Public Health and Medical Sciences

\section{Tefera Belachew Lemma}

Jimma University

\section{Lelisa Sena Dadi}

Department of Epidemiology, Faculty of Public Health, Jimma University

\section{Research article}

Keywords: determinants, first line ART failure, HIV/AIDS, Jimma Zone, Public hospitals

Posted Date: July 12th, 2019

DOI: https://doi.org/10.21203/rs.2.11281/v1

License: (c) (1) This work is licensed under a Creative Commons Attribution 4.0 International License. Read Full License 


\section{Abstract}

Background: Identifying determinant factors of antiretroviral therapy (ART) treatment failure are crucial to achieving 90-90-90 treatment target to help end AIDS epidemic by 2020. However, evidences on determinants of first line ART failure in Ethiopia are limited. Hence, the aim of this study was to assess determinants of first line ART failure among patients attending ART care in selected Public Hospitals Jimma, Southwest Ethiopia. Methods: A case control study was conducted in March 2018 on sample of 384(288 controls and 96 cases) adult people living with HIV/AIDS (PLWHA). All available cases were enrolled in the study whereas controls were selected using simple random sampling. Cases were HIV patients aged 15 years or older who were on first line ART regimen with documented treatment failure (virologic, immunologic or clinical). Controls were HIV patients aged 15 years or older who were on first line ART regimen but without evidence of therapeutic failure. Data was extracted from electronic database and supplemented by data collected through interviewer administered questionnaire. Bivariate and Multivariate logistic regression analyses were used. Adjusted odds ratios and $95 \%$ confidence interval were used to report independently associated factors with the first line ART failure at Pvalue $<0.05$. Results: Median ages of cases and controls were 28 (IQR 25-32) and 27 (IQR23-33), respectively. Being urban resident (AOR:2.2; 95\% Cl: 1.1, 3.6), smoking (AOR:5.9; 95\%Cl:3.2, 10.8), Khat use (AOR:2.2; 95\% Cl:1.3,3.7), poor treatment adherence (AOR: 2.2; 95\% Cl: 1.1,4.5), tuberculosis coinfection (AOR: 3.9; 95\% Cl:2.2, 6.8), prior exposure to ART (AOR: 3.8; 95\% Cl:1.7, 8.1), zidovudine based regimen (AOR: $4.8 ; 95 \% \mathrm{Cl}: 2.5,9.0$ ) and median duration on treatment of more than 73 months (AOR:1.9; $95 \%$ $\mathrm{Cl}: 1.2,3.3)$ were independently associated with first line treatment failure. Conclusions: Multiple factors such as being urban resident, TB co-infection, poor treatment adherence, and zidovudine based regiment were independently associated with first line ART failure. Thus, strategies designed to curb the HIV pandemic should focus on these factors, among others, to achieve the ambitious target of ending AIDS pandemic by 2020 set by UNAIDS. Key words: determinants, first line ART failure, HIV/AIDS, Jimma Zone, Public hospitals

\section{Background}

Globally, it is estimated that 36.9 million people were living with HIV during 2017. SubSaharan Africa (SSA) remains significantly affected, accounting for $69.5 \%$ of the people living with HIV (PLWHA). Ethiopia is among the SSA countries most affected by Human Immunodeficiency Virus/acquired immunodeficiency syndrome (HIV/AIDS) with an estimated 710,000 people living with HIV in 2016 [1,2]. The introduction of highly active antiretroviral therapy (HAART) was a critical milestone in the history of HIV disease resulting in dramatic reduction of morbidity and mortality, and improvement in quality of life of PLWHA [3-5].

Despite considerable reduction of morbidity and mortality due to HIV/AIDS after start of HAART, a significant proportion of patients fail to attain the intended target of viral load suppression to therapy and many of them experience clinical deterioration attributable to 
ART failure. Treatment failure occurs when combination of ARV regimen fails to control HIV infection. This could be virologic, immunologic and/or clinical failure $[6,7]$.

Virologic failure occurs when plasma viral load is 1000 copies/ml and above in two consecutive measurements within three month interval with adherence support after at least six months of using ART. Immunologic failure occurs when CD4 cell count is lowered to 250 cells $/ \mathrm{mm}^{3}$ or below following clinical failure, or persistent CD4 cells level below 100 cells $/ \mathrm{mm}^{3}$. Clinical failure is the occurrence of new or recurrent WHO clinical stage four conditions. Currently, WHO recommends viral load testing as the preferred monitoring approach to diagnose and confirm ART treatment failure. However, targeted viral load monitoring or CD4 cell count and clinical monitoring should be used to diagnose treatment failure in settings where viral load test is not routinely available $[2,7]$.

ART failure is a major challenge to HIV/AIDS management in resource limited settings including Ethiopia where the diagnosis and management of ART failure is key problem [8]. Documented finding showed that Virologic and Immunologic failure was 23\% and $21.6 \%$ among PLWHA who were on ART as reported from Vietnam and India respectively $[9,10]$. In SSA countries, rates of first line ART failure vary between $11.1 \%$ and $24 \%$ [11]. Studies showed that, East Africa has faced high prevalence of immunologic failure which ranges from $8 \%$ to 57\%; studies from South Africa indicated that 19\% of PLWHA had developed virologic and immunologic failure [12,13].

In Ethiopia, first line ART treatment failure was 19.8\% (immunologic 15\%, clinical 6.3\%, and virologic failure 1.3\%) in adult PLWHA who were on ART according to the report from private health facilities in Addis Ababa; Immunologic and clinical failure were $13.8 \%$ and $17.3 \%$ respectively as reported from South west Ethiopia [14,15]. Documented findings from University of Gondar referral hospital, Debremarkos, St. Luke and Tulubolo hospitals showed that immunologic failures were be $22.2 \%, 21 \%$, and $6.8 \%$, respectively [16-18].

Previous studies reported that various factors including being male gender [19], illiterate [20], widower [21], poor adherence and treatment interruption [22-25], WHO clinical stage III and/or IV [21,22,25,26], low CD4 cell at ART initiation [6, 19, 26, 27], presence of opportunistic infections [6, 22, 25], low BMI [6, 28], taking ARV regimen before ART initiation [22,23], taking Stavudine and Zidovudine (AZT) based regimen [29], TB coinfection [27,30,31], substance use [32-34] and longer duration on ART [3, 20, 26, 35] were significantly associated with first line ART failure.

Investigating and managing determinant factors of first line ART treatment failure is very important to achieve the viral load suppression target of the 90-90-90 by 2020 to end AIDS 
epidemic and sustain the quality of life [36]. However, there is limited evidence on the determinant factors of first line antiretroviral treatment failure among PLWHA who are on first line HAART in the study area. Therefore, this study aimed to identify the determinant factors of first line antiretroviral treatment failure among patients who were on first line ART in public hospitals of Jimma Zone, Southwest Ethiopia.

\section{Methods}

\subsection{Study Design and Setting}

Hospital based case control study was conducted from March 1 to 26/ 2018 in public hospitals of Jimma Zone, Southwest Ethiopia; namely Jimma University Specialized Hospital (JUSH), Shenen Gibe Hospital, Agaro Hospital and Limu Genet Hospital. Jimma zone is one of the administrative zones in Oromia Regional State, located at $352 \mathrm{~km}$ from Addis Ababa. According to the zonal health department information, the zone had an estimated total population of 3,324,912 in the year 2017. The hospitals have been providing ART service for a long period and have maintained data of the patients in electronic medical record database. There were 11,186 PLWHA taking HIV chronic care services during the data collection period. The study hospitals provide both first and second line ART. However, viral load testing service for HIV care has been available only in JUSH since 2015.

\subsection{Study Participants, Sample Size Determination and Sampling Technique}

All PLWHA adults aged $\geq 15$ years who had follow up of HAART between January 2004 and December 2017 were considered to be source population of the study. A Case was defined to be HIV patient aged $\geq 15$ years who was on HAART for 12 months and more documented to have first line ART treatment failure either virologic, immunologic or clinical in the study hospitals. Controls were patients aged $\geq 15$ years who were on HAART but who did not show evidence of first line ART treatment failure during the same period. PLWHA who were stayed on HAART for less than six months and PLWHA who had incomplete relevant clinical data were excluded from the study.

Epi Info ${ }^{\mathrm{TM}} 7$ StatCalc was used to determine sample size by considering the significant determinant factor of first line ART failure (age < 35 years) from previous study [35] using power $83 \%$. Therefore, total sample size was estimated to be 386 (289 controls and 97 cases; considering three to one controls to case ratio). There were 102 documented PLWHA failed first line ART treatment; however, six of them were excluded because of 
incomplete relevant clinical data form their medical record cards whereas all the remaining 96 were included in the study without sampling because of their relative small number. Desired number of controls $(\mathrm{n}=288$ ) who fulfilled the inclusion criteria were randomly selected using computer generated random numbers based on unique ART identification number. Proportion to sample size allocation was used to allocate the sample for each hospitals.

\subsection{Data Collection Tools and Procedure}

The sources of data for this study were both secondary and primary data. Secondary data was extracted from electronic database using structured checklist. Primary data was obtained using structured interviewer administered questionnaire. Data collection tools were prepared by adapting and contextualizing WHO standard tool and Federal Ministry of Health of Ethiopia ART guideline as well as by reviewing related literatures [37, 38]. Sociodemographic profiles, substance use and treatment support, and HIV care services were included in structured interviewer administered questionnaire. Body mass index, laboratory test results, ARV drugs and patient clinical status were also included in the checklist. Body mass index was measured directly as well as retrieved from the database. However, laboratory test results were retrieved from the database.

Ten nurses (six data collectors and four supervisors) who have prior experience in HIV care were recruited for data collection. The data collectors and supervisors were adequately trained before commencement of data collection. The primary data was collected on the day of scheduled clinic visit for all cases and randomly selected controls. Participants, who were not available at the time of scheduled clinic visit were traced using phone number and home address available on the card and interviewed on the consecutive days of the study period. For the secondary data, data collectors from ART clinic were accessed and reviewed electronic database and patient charts.

\subsection{Study Variables}

Dependent variable was occurrence of first line antiretroviral treatment failure. In this study, first line antiretroviral treatment failure was defined as the fulfillment of either virologic, immunologic or clinical failure criteria set by WHO. This was determined by reviewing whether the client was diagnosed with first line ART failure or not on his/her medical record. The independent variables include: socio-demographic and economic 
variables (age, residence, sex, religion, ethnicity, marital status, house hold relative wealth index, HIV disclosure status, missed clinic appointment, educational status, employment status), substance use (smoking, Khat chewing and alcohol consumption), adherence status (good, poor or fair), clinical, hematologic and ARVs related characteristics (history of opportunistic infections, functional status, history of TB coinfection, body mass index, and hemoglobin status and ARVs related factors) and treatment supports.

\subsection{Data Quality Assurance, Processing and Statistical Analysis}

Data collectors and supervisors were trained on data collection tools. Collected data entered into Epi Data version 3.1 and exported to SPSS version 23 for analysis. Simple frequencies were carried out to check data cleanness. Descriptive statistics including median values and frequencies were used to summarize participant's characteristics in each group. Dimension reduction using factorial analysis by a method of principal components was employed to assess individual's wealth index. Assumptions of principal component analysis such as measure of sampling adequacy (MSA) less than 0.5, overall Kaiser-Meyer-Olkin (KMO) value less than 0.5 , communality value less than 0.5 and complex structure were checked for each variable. Variables with p-value $<0.25$ at bivariate analysis level were taken to multivariate logistic regression analysis. The multivariable model was fitted to identify the independent determinants of first line ART failure using backward stepwise removal method. The model fitness was checked by Hosmer-Lemeshow goodness of fit tests (chi-square at 6.57 and p-value=0.583). Finally, variables that had significant associations with first line ART failure were identified and reported based on the adjusted odds ratio (AOR) with corresponding 95\% CI at p-value $\leq 0.05$.

\section{Results}

Socio-demographic characteristics of the study participants

Median age at the time of ART initiation for cases and controls were 28 (IQRs 25-32) and 27 (IQRs23-33), respectively. Female participants were 53 (55.2\%) and 181 (62.8\%) among cases and controls, respectively; more than half of cases (59.4\%) and controls (60.4\%) were in marriage, among cases and controls, those who work in private business were 52 (54.2\%) and $116(40.3 \%)$ respectively. Nearly, a quarter of cases (28.1\%) and $(23.3 \%)$ controls were belonging to second quintile wealth index status; 43 (44.8\%) of the cases and $148(51.4 \%)$ of the controls have attained primary education. More than half of the cases (59.3\%) and controls (51.4\%) were Christians whereas 77 (80.2\%) of the cases and 186 
(64.6\%) of the controls were urban inhabitants; 74 (77.1\%) of the cases and 218 (75.7\%) of the controls had disclosed their HIV status [Table 1].

Table 1 Sociodemographic Characteristics of PLWHA $\geq 15$ years, who have had follow-up at selected public hospitals of Jimma Zone, Southwest Ethiopia, 2004-2017

\begin{tabular}{cccc}
\hline Variable & Categories & Cases n (\%) & Controls n (\%) \\
\hline Age, years & Median & 28(IQR 25-32) & 27(IQR 23-33) \\
& $<28$ years & $41(42.7)$ & $149(51.7)$ \\
& $\geq 28$ years & $55(57.3)$ & $139(48.3)$ \\
\cline { 2 - 4 } Sex & Male & $43(44.8)$ & $107(37.2)$ \\
& Female & $53(55.2)$ & $181(62.8)$ \\
Marital Status & Married & $57(59.4)$ & $174(60.4)$ \\
& Single & $6(6.3)$ & $30(10.4)$ \\
\cline { 2 - 4 } & Divorced & $22(22.9)$ & $44(15.3)$ \\
\cline { 2 - 4 } Occupation & Widowed & $11(11.5)$ & $40(13.9)$ \\
Status & Government employee & $20(20.8)$ & $83(28.8)$ \\
& Private business & $52(54.2)$ & $116(40.3)$ \\
& Student & $4(4.2)$ & $8(2.8)$ \\
& Unemployed & $3(3.1)$ & $11(3.8)$ \\
\cline { 2 - 4 } & House wife & $7(7.3)$ & $45(15.6)$ \\
Wealth & Farmer & $10(10.4)$ & $25(8.7)$ \\
Index & First Quintile & $16(16.7)$ & $44(15.3)$ \\
& Second Quintile & $27(28.1)$ & $67(23.3)$ \\
& Third Quintile & $14(14.6)$ & $64(22.2)$ \\
& Fourth Quintile & $19(19.8)$ & $56(19.4)$ \\
\hline Disclosure & Fifth Quintile & $20(20.8)$ & $57(19.8)$ \\
Status & Yes & $74(77.1)$ & $218(75.7)$ \\
Missed & No & $22(22.9)$ & $70(24.3)$ \\
nppointment & Yes & $52(54.2)$ & $126(43.8)$ \\
\hline & No & $44(45.8)$ & $162(56.2)$ \\
\hline
\end{tabular}

\section{Substance use characteristics}

Among the study participants, 58 (60.4\%) cases and 129 (44.8\%) controls had history of substance use where 44 (45.8\%) of the cases and 91 (31.6\%) of the controls reported to have used Khat. More than one-third of the cases (36.5\%) and closely one in five of the controls (18.1\%) reported to have used tobacco products whereas a quarter of the cases (25.0\%) and similar proportion of the controls (24.0\%) have used alcoholic beverages [Table 2].

Table 2 Behavioral related information of PLWHA $\geq 15$ years, who have had follow-up at selected public hospitals Jimma: 2004-2017 


\begin{tabular}{|c|c|c|c|}
\hline Variable & Categories & $\begin{array}{c}\text { Cases n } \\
(\%)\end{array}$ & $\begin{array}{c}\text { Controls n } \\
(\%)\end{array}$ \\
\hline \multirow[t]{2}{*}{ History of substance use } & Yes & $58(60.4)$ & $129(44.8)$ \\
\hline & No & $38(39.6)$ & $159(55.2)$ \\
\hline \multirow{2}{*}{ Tobacco products(smoking) } & Yes & 35 (36.5) & 52 (18.1) \\
\hline & No & 61 (63.5) & 236 (81.9) \\
\hline \multirow[t]{2}{*}{ Alcoholic beverages } & Yes & $24(25.0)$ & $69(24.0)$ \\
\hline & No & $72(75.0)$ & 219 (76.0) \\
\hline \multirow{2}{*}{ Khat Chewing } & Yes & $44(45.8)$ & $91(31.6)$ \\
\hline & No & $52(54.2)$ & $197(68.4)$ \\
\hline \multirow[t]{3}{*}{ Frequency of using tobacco products } & Never & 61 (63.5) & 236 (81.9) \\
\hline & Daily & $13(13.5)$ & $16(5.6)$ \\
\hline & $\begin{array}{c}\text { Once/twice a } \\
\text { Week }\end{array}$ & $22(22.9)$ & $36(12.5)$ \\
\hline \multirow{3}{*}{$\begin{array}{l}\text { Frequency of using Alcoholic } \\
\text { beverages }\end{array}$} & Never & $72(75.0)$ & $220(76.4)$ \\
\hline & Daily & $8(8.3)$ & 46 (16.0) \\
\hline & $\begin{array}{c}\text { Once/twice a } \\
\text { Week }\end{array}$ & $16(16.7)$ & $22(7.6)$ \\
\hline \multirow{3}{*}{ Frequency of using Khat } & Never & $52(54.2)$ & 197 (68.4) \\
\hline & Daily & 40 (41.7) & $57(19.8)$ \\
\hline & $\begin{array}{c}\text { Once/twice a } \\
\text { Week }\end{array}$ & $4(4.1)$ & $34(11.8)$ \\
\hline
\end{tabular}

Adherence and Antiretroviral drug related characteristics

The study revealed that 70 (72.9\%) and 261(90.6\%) cases and controls had good baseline adherence to ARVs, respectively. Majority of the cases (93.8\%) and controls (97.9\%) have good current adherence to ARVs. Among the cases 30 (31.3\%) and 38 (39.6\%) of them used TDF-3TC-EFV and AZT-3TC-NVP initial ARV regiment, respectively. However, 154(53.5\%) and 35(12.2\%) of the controls used TDF-3TC-EFV and AZT-3TC-NVP initial ARV regiment, respectively. Regarding to prior exposure of ARVs, a third (33.3\%) of the cases but small proportion (6.9\%) of the controls had history of exposure to some ARVs before becoming eligible for ART due to PEP and PMTCT. More than half of the cases (63.5\%) and below half $(45.8 \%)$ of the controls were on HAART for more than median duration of 73 months [Table 3].

Table 3 Antiretroviral medication related information of PLWHA $\geq 15$ years, who have had follow-up at selected public hospitals Jimma: 2004-2017 


\begin{tabular}{lccc}
\hline Variable & Categories & Cases n (\%) & Controls n (\%) \\
\hline Baseline adherence to treatment & Good & $70(72.9)$ & $261(90.6)$ \\
& Fair/poor & $26(27.1)$ & $27(9.4)$ \\
Current adherence to treatment & Good & $90(93.8)$ & $282(97.9)$ \\
& Fair/poor & $6(6.3)$ & $6(2.1)$ \\
Prior ARV exposure & Yes & $32(33.3)$ & $20(6.9)$ \\
& No & $64(66.7)$ & $268(93.1)$ \\
Reason for taking ARVs prior to ART & PMTCT & $3(3.1)$ & $4(1.4)$ \\
& PEP & $23(24.0)$ & $5(1.7)$ \\
& Unspecified & $6(6.3)$ & $11(3.8)$ \\
ARV interruption & Non-users & $64(66.7)$ & $268(93.1)$ \\
Initial ARV regimen & Yes & $54(56.3)$ & $58(20.1)$ \\
& No & $42(43.8)$ & $230(79.9)$ \\
& TDF-3TC-EFV & $30(31.3)$ & $154(53.5)$ \\
& D4T-3TC-NVP & $13(13.5)$ & $52(18.1)$ \\
& AZT-3TC-NVP & $38(39.6)$ & $35(12.2)$ \\
& D4T-3TC-EFV & $4(4.2)$ & $21(7.3)$ \\
Duration on HAART & AZT-3TC-EFV & $7(7.3)$ & $13(4.5)$ \\
& TDF-3TC-NVP & $4(4.2)$ & $13(4.5)$ \\
& Median & $84.5(60-103.8)$ & $67.5(35-108)$ \\
& <73months & $35(36.5)$ & $156(54.2)$ \\
& $\geq 73 m o n t h s$ & $61(63.5)$ & $132(45.8)$ \\
\hline
\end{tabular}

\section{Clinical Characteristics of the Study Participants}

More than half of the cases (54.2\%) and the controls (60.4\%) had other opportunistic infection at baseline. Above half (55.2\%) of cases and slightly above a quarter $(26.7 \%)$ of the controls had TB coinfection at the time of ART initiation. Two-third (66.6\%) of cases and three-fourth (74.7\%) of the controls had working functional status at the time of ART initiation. Concerning BMI, 45(46.9\%) of the cases had median BMI $<19.3 \mathrm{~kg} / \mathrm{m}^{2}$, whereas slightly above half (51.0\%) of the controls had median $\mathrm{BMI}<19.3 \mathrm{~kg} / \mathrm{m}^{2}$ at baseline [Table 4].

Table 4 Clinical related information of PLWHA $\geq 15$ years, who have had follow-up at selected public hospitals Jimma: 2004-2017 


\begin{tabular}{lccc}
\hline Variable & Categories & Cases n (\%) & Controls n (\%) \\
\hline HIV testing entry & VCT & $41(42.7)$ & $114(39.6)$ \\
& PITC & $19(19.8)$ & $62(21.5)$ \\
& PMTCT & $7(7.3)$ & $19(6.6)$ \\
& Other* & $29(30.2)$ & $93(32.3)$ \\
Baseline opportunistic infection & Yes & $52(54.2)$ & $174(60.4)$ \\
& No & $44(45.8)$ & $114(39.6)$ \\
Current opportunistic infection & Yes & $11(11.5)$ & $24(8.3)$ \\
& No & $85(88.5)$ & $264(91.7)$ \\
TB coinfection at ART initiation & Yes & $53(55.2)$ & $77(26.7)$ \\
Baseline functional status & No & $43(44.8)$ & $211(73.3)$ \\
& Working & $64(66.6)$ & $215(74.7)$ \\
Current functional status & Ambulatory & $26(27.1)$ & $62(21.5)$ \\
& Bed ridden & $6(6.3)$ & $11(3.8)$ \\
& Working & $92(95.8)$ & $278(96.5)$ \\
Baseline BMI kg/m ${ }^{2}$ & Ambulatory & $3(3.1)$ & $9(3.1)$ \\
& Bed ridden & $1(1.0)$ & $1(0.3)$ \\
& Median & $18.9(\mathrm{IQR} 16.0-21.5)$ & $19.4(\mathrm{IQR} 17.6-21.8)$ \\
& $<19.3 \mathrm{~kg} / \mathrm{m}^{2}$ & $45(46.9 \%)$ & $147(51.0 \%)$ \\
Current BMI kg/m ${ }^{2}$ & $\geq 19.3 \mathrm{~kg} / \mathrm{m}^{2}$ & $51(53.1 \%)$ & $141(49.0 \%)$ \\
& Median & $21.6(\mathrm{IQR} 18.7-23.6)$ & $21.4(\mathrm{IQR} 19.4-24.0)$ \\
& $<21.5 \mathrm{~kg} / \mathrm{m}^{2}$ & $51(53.1 \%)$ & $142(49.3 \%)$ \\
& $\geq 21.5 \mathrm{~kg} / \mathrm{m}^{2}$ & $45(46.9 \%)$ & $146(50.7 \%)$ \\
\hline
\end{tabular}

\section{Hematologic Profile of the Study Participants}

In this study 41(42.7\%) of the cases and 91(31.6\%) of the controls had baseline median Hemoglobin level less than 12g/dl (IQR:11-12.8) and 12g/dl (IQR:11.2-13.1), respectively; $40(41.7 \%)$ of the cases and 88(30.6\%) of the controls had current median Hemoglobin level less than 13g/dl (IQR: 12.4-14.1) and 13g/dl (IQR: 12.5-14.1), respectively[Table 5].

Table 5 Hematologic Profile of PLWHA $\geq 15$ years, who have had follow-up at selected public hospitals Jimma: 2004-2017

\begin{tabular}{lccc}
\hline Variable & Categories & Cases n (\%) & Controls n (\%) \\
\hline Baseline hemoglobin status(median) & Median & 12(IQR11-12.8) & 12(IQR11.2-13.1) \\
& $\geq 12 \mathrm{~g} / \mathrm{dl}$ & $55(57.3)$ & $197(68.4)$ \\
& $<12 \mathrm{~g} / \mathrm{dl}$ & $41(42.7)$ & $91(31.6)$ \\
Current hemoglobin status (median) & Median & 13(IQR 12.4-14.1) & $13(\mathrm{IQR} 12.5-14.1)$ \\
& $\geq 13 \mathrm{~g} / \mathrm{dl}$ & $56(58.3)$ & $200(69.4)$ \\
& $<13 \mathrm{~g} / \mathrm{dl}$ & $40(41.7)$ & $88(30.6)$ \\
\hline
\end{tabular}




\section{Treatment support Characteristics of Study Participants}

Regarding treatment support, 47(49\%) of the cases and 182(63.2\%) of the controls had history of treatment support, where $21(21.9 \%)$ of the cases and $80(27.8 \%)$ of the controls had emotional support; $22(22.9 \%)$ of the cases and 76(26.4\%) of the controls had physical support; $23(24.0 \%)$ of the cases and $118(41.0 \%)$ of the controls have got the supports from their family whereas $19(19.8 \%)$ of the cases and 39 (13.5\%) of the controls reported to have obtained the supports from governmental organizations.

\section{Determinant Factors Associated with First line ART Treatment failure}

After controlling for possible confounders, being urban resident, smoking, Khat use, poor baseline adherence status, TB coinfection at the time of ART initiation, previous exposure to ARV, taking AZT based first line ARV regiment, median duration on HAART for $\geq 73$ months were found to be significantly associated with first line ART treatment failure. However: age, sex, marital status, occupational status, household wealth index status and body mass index were not significantly associated with first line ART treatment failure.

The first line treatment ART failure occurs two times (AOR:2.2; 95\% CI:1.1, 3.6) more likely among urban residents compared to their counterparts. The first line ART treatment failure was about six times (AOR:5.9; 95\% CI: 3.2,10.8) more likely among smokers compared to non-smokers. The first line ART treatment failure was two times (AOR: 2.2; 95\% CI:1.3, 3.7) more likely Khat users compared to non-users. The failure of first line ART treatment was two times (AOR:2.2;95\%CI:1.1,4.5) more likely among poorly adherent PLWHA compared to good adherent ones.

The first line ART treatment failure was almost four times (AOR: 3.9; 95\% CI: 2.2, 6.8) more likely among PLWHA who had TB co-infection compared to those who did not have -TB coinfection. The first line ART treatment failure was about three times (AOR:3.8; 95\% CI:1.7, 8.1) more likely among PLWHA who had been exposed ARV compared to those who were not exposed to ARV prior to ART treatment. The first line ART treatment failure was closely five times (AOR:4.8; 95\% CI: 2.5, 8.0) more likely among AZT-based initial first line ARV users compared to TDF based users. The first line ART failure was two times (AOR:1.9; 95\% CI: 1.2, 3.3) more likely among PLWHA who were on HAART at least for 73 months compared to those PLWHA who were on the therapy for less than 73 months [Table 6]. 
Table 6 Determinants of First line ART failure among PLWHA $\geq 15$ years, who had followup at selected public hospitals Jimma: 2004-2017

\begin{tabular}{|c|c|c|c|c|}
\hline \multirow[t]{2}{*}{ Variables } & \multicolumn{2}{|c|}{ First line ART Failure } & \multirow{2}{*}{$\begin{array}{c}\text { Bivariate Analysis } \\
\text { COR (95\%CI) }\end{array}$} & \multirow{2}{*}{$\begin{array}{c}\text { Multivariate Analysis } \\
\text { AOR (95\%CI) }\end{array}$} \\
\hline & Cases n (\%) & Controls n (\%) & & \\
\hline \multicolumn{5}{|l|}{ Residence } \\
\hline Urban & $77(80.2)$ & $186(64.6)$ & $2.2(1.3,3.9)$ & $2.2(1.1,3.6) *$ \\
\hline Rural & $19(19.8)$ & $102(35.4)$ & 1 & 1 \\
\hline \multicolumn{5}{|l|}{ Smoking } \\
\hline Yes & 35 (36.5) & $52(18.1)$ & $2.6(1.6,4.4)$ & $5.9(3.2,10.8) *$ \\
\hline No & $61(63.5)$ & 236 (81.9) & 1 & 1 \\
\hline \multicolumn{5}{|l|}{ Khat Chewing } \\
\hline Yes & $44(45.8)$ & 91 (31.6) & $1.8(1.1,2.9)$ & $2.2(1.3,3 \cdot 7)^{*}$ \\
\hline No & $52(54.2)$ & $197(68.4)$ & 1 & 1 \\
\hline \multicolumn{5}{|c|}{ Treatment support } \\
\hline Yes & $47(49)$ & $182(63.2)$ & 1 & 1 \\
\hline No & $49(51)$ & $106(36.8)$ & $1.8(1.1,2.9)$ & $1.5(0.9,2.7)$ \\
\hline \multicolumn{5}{|c|}{ TB coinfection at ART initiation } \\
\hline Yes & $53(55.2)$ & 77 (26.7) & $3.4(2.1,5.5)$ & $3.9(2.2,6.8) *$ \\
\hline No & $43(44.8)$ & 211 (73.3) & 1 & 1 \\
\hline \multicolumn{5}{|c|}{ Baseline adherence to treatment } \\
\hline Good & $70(72.9)$ & $261(90.6)$ & 1 & 1 \\
\hline Fair/poor & $26(27.1)$ & $27(9.4)$ & $3.6(1.0,6.5)$ & $2.2(1.1,4.5)^{*}$ \\
\hline \multicolumn{5}{|c|}{ Use of ARV Prior to ART initiation } \\
\hline Yes & $32(33.3)$ & $20(6.9)$ & $6.7(3.6,12.5)$ & $3.8(1.7,8.1)^{*}$ \\
\hline No & 64 (66.7) & 268 (93.1) & 1 & 1 \\
\hline \multicolumn{5}{|c|}{ Initial first line ARV regimen ( TDF, D4T, AZT) based } \\
\hline TDF based & $34(35.4)$ & $167(58)$ & 1 & 1 \\
\hline D4T based & $17(17.7)$ & $73(25.3)$ & $1.1(0.6-2.2)$ & $0.9(0.4,1.9)$ \\
\hline AZT based & $45(46.9)$ & $48(16.7)$ & $4.6(2.7,7.0)$ & $4.8(2.5,8.0)^{*}$ \\
\hline \multicolumn{5}{|c|}{ Initial first line ARV regimen ( EFV, NVP) based } \\
\hline EFV based & $41(42.7)$ & 188(65.3) & 1 & 1 \\
\hline NVP based & $55(57.3)$ & $100(34.7)$ & $2.5(1.6,4.0)$ & - \\
\hline \multicolumn{2}{|c|}{ Duration on HAART(median) } & \multicolumn{2}{|c|}{$84.5(60-103.8)$} & $(35-108)$ \\
\hline$<73$ months & $35(36.5)$ & $156(54.2)$ & 1 & 1 \\
\hline$>=73$ months & $61(63.5)$ & $132(45.8)$ & $2.1(1.3,3.3)$ & $1.9(1.2,3.3)^{*}$ \\
\hline
\end{tabular}

\section{Discussion}

At present, the need to focus on achieving UNAID's 90-90-90 treatment target is highly emphasized. The aim of this study was to identify determinants of first line ART treatment 
failure in public hospitals. In this study, multiples independent factors were identified to be determinants of first line ART treatment failure among PLWHA who were on HAART. In this study, the odds of first line ART treatment failure was two times more likely among urban residents. This was comparable with a study done in Cameroon which showed that first line ART treatment failure was less likely to occur among patients residing far from the treatment centers as compared with near the treatment center [39]. This might be due to the good adherence status of patients residing at rural than urban as evidenced by our finding; other assumption could be urban inhabitants might face more HIV-related stigma and discrimination which resulted in poor adherence and failure to take their medication.

With regard to substances use, the present study shows that first line ART treatment failure was higher among smokers and Khat users. This finding was in tandem with the study findings from Ethiopia [33] and Vietnam [19]. This might be due to the fact that using ARV drugs and substances simultaneously, would prone to mental health problems resulted in poor adherence characterized by failure to take medication properly; moreover interrupting the medication which leads finally to first line ART treatment failure [34].

The odds of first line ART treatment failure was higher among base line poor adherents compared to good adherent. This finding is in line with findings of studies conducted in Ethiopia [8,14,35,40], South Africa [12], Tanzania [13], Rwanda [24] and Kenya [31]. Possibly this might be due to the reality that poor adherence can predispose patients to take medications improperly; moreover, interrupting the therapy and hence allow more viral replication which in turn increases infection of more CD4 cells and eventually depletion of their number and hastening to advanced stage of HIV finally resulted in first line ART treatment failure.

The odds of first line ART treatment failure was higher among PLWHA who had TB coinfection compared to those who did not have TB co-infection. This is comparable with findings reported from Ethiopia [30,40] and Nigeria [28]. This might be due to the fact that TB infection impairs cellular immune responses through Tuberculosis-induced apoptosis of CD4 cells which subsequently lead to depletion of CD4 cells and resulting in first line ART treatment failure [17]. The odds of first line ART treatment failure was higher among PLWHA who had history of exposure to any type of ARV prior to ART initiation compared to their counterparts. This finding is in tandem with the findings from South Africa [12, 23] and Peru [22]. This might be due to poor adherent to ARVs because of the drugs adverse effect [43]. The odds of first line ART treatment failure higher among AZT based users compared to TDF based first line ART regimen. This finding is comparable with the study findings from Tanzania [29] and Kenya [31]. This might be due to the fact that AZT induces more adverse effects including severe anemia, nausea and vomiting that might contributed to reduced treatment adherence [31]. 
The odds of first line ART treatment failure was higher among PLWHA who were on HAART for more than 73 months compared to their counter parts. This finding is comparable to study findings from Ethiopia [35] and Swaziland [26]. This might be due to the fact that being on HAART long duration increases the probability of experiencing poor adherence and drug interruption which might be resulted in treatment failure [35]. However, in contrast to this a study from Woldia hospital, Ethiopia revealed that first line ART treatment failure was less likely occurred among PLWHA who were on ART for longer duration (mean duration on ART were 48.4 and 76.5 months for cases and controls, respectively) [3].

The present study has some limitations; this study has made use of secondary data where measuring the adherence status of the patients is based on health care providers' assessment, which is inadequate to detects poor adherence even though this method is often in clinical practice in the Ethiopian context. Again, virologic, immunologic or clinical methods were used for the diagnosis of first line ART treatment failure; however, measuring treatment failure with immunologic or clinical have poor sensitivity and specificity to detect first line ART treatment failure. Finally, as a case control study, this study might faced recall bias regarding to the information given by the study participants.

\section{Conclusion}

Finally, the study revealed that being urban inhabitant, smoking, Khat chewing, poor baseline adherence, TB coinfection, exposed to any type of ARV prior to ART initiation, taking AZT based initial first line ARV and 73 months and more duration on HAART were identified to be the independent determinant factors of first line ART treatment failure.

Health workers need to dedicate time with every patient to provide enhanced adherence counselling to improve adherence of patients towards ARV medication particularly for PLWHA who are urban inhabitant, smokers, Khat chewers and those who stayed on HAART for longer duration. Focus should be given on early screening and management of tuberculosis and other opportunistic infection among PLWHA. Monitoring and follow up of adherence and ensuring proper use of ARVs is important to reduce failure of the first line ART among the PLWHA who take ARVs for PEP. Physicians and other health workers should have strengthened monitoring and evaluating adverse effects of ARVs and decide changing medications when it is mandatory. The findings of this study indicate the need for more dedication and effort from both health care providers and clients to act on the determinants so as to sustain the long term efficacy of HAART and hence, achieving the ambitious target of 2020 . 


\section{Abbreviations}

ART: Antirretroviral Therapy; BMI: Body Mass Index; D4T: Stavudine; IQR: Inter Quartile Range; PLWHA: People Living with HIV/AIDS; PMTCT: Prevention of Motherto-Child Transmission SSA: Sub-Saharan Africa; TB: Tuberculosis; 3TC: Lamivudine; AIDS: Acquired Immune Deficiency Syndrome; AOR: Adjusted Odds Ratio; ARV: Antiretroviral; AZT/ZDV: Zidovudine; CI: Confidence Interval; EFV: Efavirenz; HAART: Highly Active Antiretroviral Therapy; HIV: Human Immunodeficiency Virus; NNRTI: Non-Nucleoside Reverse-Transcriptase Inhibitor NRTI: Nucleoside ReverseTranscriptase Inhibitor; NVP: Nevirapine PEP: Post-Exposure Prophylaxis; TDF: Tenofovir Disoproxil Fumarate; UNAIDS: Joint United Nations Program on HIV/AIDS; WHO: World Health Organization

\section{Declarations}

\section{Ethics approval and consent to participate}

Ethical approval was obtained from Jimma University Institute of Health Ethical Review Committee. Written informed consent was obtained from each study participant before conducting the interviews. The confidentiality of information obtained from each study participant was ensured through anonymity. The findings of the study is communicated in an aggregated form where individual information cannot be disclosed in any way.

\section{Consent for publication}

Not applicable

\section{Availability of data and material}

The datasets generated and/or analyzed during the current study are available from the corresponding author on reasonable request.

\section{Competing interests}

The authors declare that they have no competing interests

\section{Funding:}

This study was funded by Jimma University. The views presented in the article are of the author and not necessarily express the views of the funding organization.

\section{Authors' contributions'}


ABA, ANT, LSD and TS: Involved in the inception, design, data acquisition, analysis and interpretation, and wrote the manuscript. EKG and TBL: participated in design, data acquisition and analysis, administrative matters and reviewing the manuscript. MG and DA: Participated in data acquisition, data management and analysis as well as critically reviewing the manuscript.

\section{Acknowledgements}

The study participants are greatly acknowledged for their cooperation. Research assistants are also acknowledged for tirelessly collecting, supervising and encoding the data. Finally, Jimma University is highly acknowledged for covering the cost of the study.

\section{References}

[1]. UNAIDS. Global HIV Statistics. Geneva, Switherland, Joint United Nations Programme on HIV/AIDS; 2018.

[2]. Joint United Nations Program on HIV/AIDS. Global report: UNAIDS report on the global AIDS epidemic. Geneva 27 Switzerland: UNAIDS/JC2910E; 2017. 12-30 p.

[3]. Babo YD, Alemie GA, Fentaye FW. Predictors of first-line antiretroviral therapy failure amongst HIV-infected adult clients at Woldia Hospital , Northeast Ethiopia. PLoS One. 2017;12(11):1-19.

[4]. Leng X, Liang S, Ma Y, Dong Y, Kan W, Goan D, et al. HIV virological failure and drug resistance among injecting drug users receiving fi rst-line ART in China. 2014;1-8.

[5]. WHO. World Health Organization. The use of antiretroviral drugs for treating and preventing hiv infection. Second Edi. Geneva, Switzerland; 2016. 99-152, 402 p.

[6]. Patrikar S, Shankar S, Kotwal A, Basannar DR, Bhatti V, Verma R, et al. Predictors of first line antiretroviral therapy failure and burden of second line antiretroviral therapy. Med J Armed Forces India. 2017 Jan 1;73(1):5-11.

[7]. Subhasish Kamal Guha DM. Management of Failure of Antiretroviral Treatment. In: Management of Failure of Antiretroviral Treatment. 2016. p. 140-1. 
[8]. Haile D, Takele A, Gashaw K, Demelash H, Nigatu D. Predictors of Treatment Failure among Adult Antiretroviral Treatment ( ART ) Clients in Bale Zone Hospitals, South Eastern Ethiopia. PLoS One. 2016;11(10):p 2-8.

[9]. Allam RR, Murhekar M V, Bhatnagar T, Uthappa CK, Nalini C. Predictors of immunological failure and determinants of suboptimal CD4 testing among adults with HIV on first-line antiretroviral therapy in Andhra Pradesh , India , 2008 - 2011. Trans R Soc Trop Med Hyg. 2017;109(March 2015):325-33.

[10]. Huong DTM, Bannister W, Phong PT, Kirk O, Peters L, Mih B, et al. Haiphong, Vietnam Factors associated with HIV-1 virological failure in an outpatient clinic for HIVinfected people in Factors associated with HIV-1 virological failure in an outpatient clinic for HIV-infected people in Haiphong, Vietnam. Int J STD AIDS [Internet]. 2011 [cited 2017 Nov 4];22(659):659-64.

[11]. Hawkins C, Ulenga N, Liu E, Aboud S, Mugusi F, Chalamilla G, et al. HIV virological failure and drug resistance in a cohort of Tanzanian HIV-infected adults. Joural Antimicrob Chemother. 2016;71(10.1093/jac/dkw051):1966-74.

[12]. El-khatib Z, Katzenstein D, Marrone G, Laher F, Mohapi L, Morris L, et al. Adherence to Drug-Refill Is a Useful Early Warning Indicator of Virologic and Immunologic Failure among HIV Patients on First-Line ART in South Africa. 2011;6(3):1-10.

[13]. Kapesa A, , Daniel Magesa, Alexander William, John Kaswija4 , Jeremiah Seni CM. D eterminants of immunological failure among clients on the first line treatment with highly active antiretroviral drugs in D ar es S alaam, T anzania. Asian Pac J Trop Biomed. 2014;4((suppl2)):s620-624.

[14]. Biset Ayalew et al, Istri C, Dharma S, Sawitri AAS, M TP. Factors associated to first line antiretroviral therapy ( ART ) failure among HIV / AIDS patients at Sanglah Hospital , Bali. Dovepress [Internet]. 2017 [cited 2017 Oct 29];8(10.2147/HIV):4-11.

[15]. Yimer YT, Yalew AW. Magnitude and Predictors of Anti-Retroviral Treatment ( ART ) Failure in Private Health Facilities in Addis Ababa , Ethiopia. Open Access. 2015;10(5):117.

[16]. Melsew YA, Terefe MW, Tessema GA, Ayele TA. AIDS \& Clinical Rate of Immunological Failure and its Predictors among Patients on Highly Active Antiretroviral Therapy at Debremarkos Hospital , Northwest Ethiopia: A Retrospective Follow up Study. Open Access. 2013;4(5):1-4.

[17]. Assefa A, Gelaw B, Getnet G, Yitayew G. The effect of incident tuberculosis on immunological response of HIV patients on highly active anti-retroviral therapy at the 
university of Gondar hospital, northwest Ethiopia: a retrospective follow-up study. BMC Infect Dis [Internet]. 2014 Dec 27 [cited 2017 Oct 29];14(468):1-8.

[18]. Bekelech Bayou, Abay Sisay,\& AK. Assessment of the magnitude and associated factors of immunological failure among adult and adolescent HIV-infected patients in St. Luke and Tulubolo Hospital, Oromia Region, Ethiopia. PanAfrican Med J. 2015;21(291):110.

[19]. Pollack TM, Duong HT, Pham TT, Do CD, Colby D. Cigarette smoking is associated with high HIV viral load among adults presenting for antiretroviral therapy in Vietnam. PLoS One. 2017;12(3):1-11.

[20]. Pou C, Maculuve S, Ceden S, Luis L, Rodrı J, Clotet B, et al. Determinants of virological failure and antiretroviral drug resistance in Mozambique. Joural Antimicrob Chemother. 2017;70(November):2639-47.

[21]. Istri C, Dharma S, Sawitri AAS, M TP. Factors associated to first line antiretroviral therapy ( ART ) failure among HIV / AIDS patients at Sanglah Hospital , Bali. Public Heal Prev Med Arch examined. 2017;5(1):4-11.

[22]. Willig J, Juan EZ. NIH Public Access. NIH Public Access. 2014;30(1):42-8.

[23]. Datay MI, Boulle A, Sa F, Mant D, Yudkin P. Associations With Virologic Treatment Failure in Adults on Antiretroviral Therapy in South Africa. Lippincott Williams \& Wilkins. 2010;54(5):489-95.

[24]. Ndahimana J d'Amour, Riedel DJ, Mwumvaneza M, Sebuhoro D, Uwimbabazi JC, Kubwimana M, et al. Drug resistance mutations after the first 12 months on antiretroviral therapy and determinants of virological failure in Rwanda. Trop Med Int Heal [Internet]. 2016 Jul [cited 2017 Oct 29];21(7):928-35.

[25]. Bangure D, Mungati M, Chemhuru M. Factors Associated with Human Immunodeficiency Virus First Line Treatment Failure in Zvishavane District ,. Austin J HIV/AIDS Res. 2015;2(1):1-6.

[26]. Jobanputra K, Parker LA, Azih C, Okello V, Maphalala G, Kershberger B, et al. Factors Associated with Virological Failure and Suppression after Enhanced Adherence Counselling , in Children, Adolescents and Adults on Antiretroviral Therapy for HIV in Swaziland. PLoS One. 2015;10(2):1-12.

[27]. Ma Y, Zhao D, Yu L, Bulterys M, Robinson ML, Zhao Y, et al. Predictors of Virologic Failure in HIV-1 - Infected Adults Receiving First-Line Antiretroviral Therapy in 8 Provinces in China. HIV/AIDS. 2017;50(November). 
[28]. Musa BM, Musa B, Muhammed H, Ibrahim N. Incidence of tuberculosis and immunological profile of TB / HIV co-infected patients in Nigeria. Ann Thorac Med. 2015;10(3):185-92.

[29]. Chomboko CL, Kabyemera RM, Kidenya BR, Kamugisha E. ISSN : 2474-6916 Prevalence and Predictors of Immunological Treatment Failure among HIV Infect - ed Adults on the First-line Antiretroviral Therapy in Mbeya Region , Tanzania. Open Access. 2018;3(1):1-9.

[30]. Getnet Y. Determinants of First Line Antiretroviral Treatment Failure in Public Hospitals of Addis Ababa, Ethiopia : Unmatched Case Control Study. 2014;4(15):1-13.

[31]. Kwobah 1\# CM, Mwangi AW, Koech JK, Simiyu GN, Siika AM. Factors Associated with First - Line Antiretroviral Therapy Failure amongst HIV - Infected African Patients : A Case - Control Study*. World J AIDS [Internet]. 2012 [cited 2017 Nov 5];2:271-8.

[32]. Federal Minstry of, Health. National Guidelunes for comprehensive HIV Prevention, Care and Treatment. Addis Ababa; 2017. 1.226.

[33]. Niemeyer K, King A, Mengistu S, Hennig N. Predictors of antiretroviral therapy failure in an urban HIV / AIDS clinic in Addis Ababa , Ethiopia. Lancet Glob Heal [Internet]. 2016;4:S6.

[34]. Azmach NN. Adherence to Antiretroviral Therapy and Associated Factors Among Adult ARV Users in Arba Minch Hospital ,. Cent African J Public Heal. 2017;3(July 2003):19-26.

[35]. Bayu et al. Determinants of virological failure among patients on highly active antiretroviral therapy in University of Gondar Referral Hospital , Northwest Ethiopia : a case - control study. Dove Med Press. 2017;9(3):p153-157.

[36]. Joint United Nations Programme on HIV/AIDS (UNAIDS). Joint United Nations Programme on HIV/AIDS (UNAIDS) 90-90-90 an ambitious treatment target to help end the AIDS epidemic. Geneva 27 Switzerland; 2014. 1-40 p.

[37]. Patient monitoring guidelines for HIV care and antiretroviral therapy ( ART ). Switherland Geneva; 2004. 17-157 p.

[38]. Democratic F. Federal Democratic Republic of Ethiopia Ministry of Health National Guidelines for Comprehensive HIV Prevention, Care and Treatment. Addis Ababa, Ethiopia; 2014. p-1,61.

[39]. Meriki HD, Tufon KA, Afegenwi MH, Nyindem BA, Atanga PN, Anong DN, et al. Immuno-haematologic and virologic responses and predictors of virologic failure in HIV-1 
infected adults on first-line antiretroviral therapy in Cameroon. Open Access. 2014;3(5):111.

[40]. Hailu GG, Hagos DG, Hagos AK, Wasihun G, Dejene TA. Virological and immunological failure of HAART and associated risk factors among adults and adolescents in the Tigray region of Northern Ethiopia. OPEN ACCESS. 2018;30(5):1-17.

[41]. Knobel H, Peraire J, Domingo P, Dalmau D, Cruceta A, Arnaiz JA, et al. Original article Post-exposure prophylaxis for HIV infection : a clinical trial comparing lopinavir / ritonavir versus atazanavir each with zidovudine / lamivudine. Int Med Press. 2012;17(10):337-46. 